\title{
EXPLORANDO A BACIA HIDROGRÁFICA NA ESCOLA: CONTRIBUIÇÕES À EDUCAÇÃO AMBIENTAL
}

\author{
Exploring watershed in the school: contributions \\ to the Environmental Education
}

\author{
Melissa Bergmann ${ }^{1}$ \\ Catarina da Silva Pedrozo ${ }^{2}$
}

\begin{abstract}
Resumo: Este trabalho foi desenvolvido em duas escolas públicas do município de Giruá, RS, com a participação de professores e estudantes dos Ensinos Fundamental e Médio, com ênfase na sub-bacia do Rio Santo Cristo. Os procedimentos metodológicos consistiram na formação de grupos de professores e seleção de alunos-monitores, desenvolvendo-se atividades tais como: aula teórica, aplicação de protocolo para caracterização de bacias hidrográficas, coleta e análise de água do rio, elaboração de material educativo e apresentação da pesquisa em seminários locais e regionais. Os alunos também responderam a um questionário para verificação de seus conhecimentos antes e após as atividades desenvolvidas. A participação dos estudantes nas atividades mostrou a importância desse processo no aprendizado e na sistematização dos conhecimentos para divulgação dos trabalhos realizados para a comunidade. A Educação Ambiental nas escolas requer a consolidação de grupos de professores e de alunos-monitores para atuarem como multiplicadores na geração de conhecimentos sobre o ambiente local.
\end{abstract}

Palavras-chave: Bacia hidrográfica. Educação ambiental. Ensino Fundamental. Ensino Médio.

\begin{abstract}
This work took place in two public schools located in the city of Giruá, RS. Teachers and students from both the elementary school and high school participated actively in the process of studying the Santo Cristo River. Groups of teachers and teachers' assistants were selected to help devising a series of activities such as: theoretical classes on watersheds, applying protocols on characterizing watersheds, gathering and analyzing the quality of water from the river, writing educational guides, and presenting the ongoing work in local and regional seminars. The students also answered a questionnaire to check their knowledge before and after the activities developed. Students' participation revealed the importance of this learning process and knowledge systematization in the corresponding presentations to the community. Hence, it is really important to consolidate groups of teachers and teachers' assistants to improving knowledge generation of local environment and community participation in the environmental issues.
\end{abstract}

Keywords: Watershed. Environmental education. Elementary school. High school.

${ }^{1}$ Bióloga. Mestre em Ecologia. Docente de Biologia no Ensino Médio, Instituto Estadual de Educação João XXIII. Giruá, RS. < biomelis@yahoo.com.br >

${ }^{2}$ Bióloga. Doutora em Ecologia e Recursos Naturais. Docente, Instituto de Biociências, Universidade Federal do Rio Grande do Sul (UFRGS). Porto Alegre, RS. <catarina@ecologia.ufrgs.br>.

${ }^{1}$ Rua Arthur Ferraz de Campos, 928

Bairro Santa Fé - Giruá, RS

98.870-000 
Bergmann, M.; Pedrozo, C. S.

\section{Introdução}

A Educação Ambiental no Brasil está regulamentada pela Lei 9.795/99, que instituiu a Política Nacional de Educação Ambiental (PNEA), sendo compreendida como

os processos por meio dos quais o indivíduo e a coletividade constroem valores sociais, conhecimentos, habilidades, atitudes e competências voltadas para a conservação do meio ambiente, bem de uso comum do povo, essencial à sadia qualidade de vida e sua sustentabilidade. (BRASIL, 2001, p. 208)

Dentre os objetivos da Educação Ambiental, destacam-se: o desenvolvimento de uma compreensão integrada do meio ambiente em suas múltiplas e complexas relações, envolvendo aspectos ecológicos, legais, políticos, sociais, econômicos, científicos, culturais e éticos; o estímulo e o fortalecimento de uma consciência crítica sobre a problemática ambiental e social; o incentivo à participação individual e coletiva na preservação do equilíbrio do meio ambiente, entendendo-se a defesa da qualidade ambiental como um valor inseparável do exercício da cidadania. A Política Nacional de Educação Ambiental estabelece ainda que os estudos, pesquisas e experimentações devem-se voltar para o desenvolvimento de instrumentos e metodologias destinadas à incorporação da dimensão ambiental nos diferentes níveis e modalidades de ensino, de forma interdisciplinar, apoiando as iniciativas de experiências locais e regionais. Dessa forma, a participação das escolas e universidades deve ser incentivada em programas e atividades vinculados à Educação Ambiental na sensibilização da sociedade.

\section{O conceito de Bacia Hidrográfica $(\mathrm{BH})$ e sua utilização como unidade básica em educação ambiental}

O conceito clássico de bacia hidrográfica $(\mathrm{BH})$ explicita basicamente o conjunto de terras drenadas por um corpo d'água principal e seus afluentes, numa perspectiva hidrológica (PIRES, SANTOS, DEL PRETTE, 2002). Esse conceito, porém, vem se expandindo, uma vez que a bacia hidrográfica tornou-se uma unidade de planejamento e gerenciamento ambiental. Essa unidade é apropriada para estudos ambientais integrados, pois sobre os sistemas hidrológicos, geológicos e ecológicos de uma bacia hidrográfica atuam forças antropogênicas, onde os sistemas biogeofísicos, econômicos e sociais interagem (AB'SABER apud TUNDISI, 2003).

Bacias hidrográficas em menor escala inserem-se em regiões hidrográficas maiores. Desta forma, é importante que se relacionem os pequenos cursos de água de um município a regiões hidrográficas mais amplas. De acordo com os Parâmetros Curriculares Nacionais (PCN) do Meio Ambiente (BRASIL, 1997), o trabalho com a realidade local possui a qualidade de oferecer um universo acessível e conhecido, passível de aplicação do conhecimento. Por outro lado, os alunos precisam compreender a complexidade e a amplitude das questões ambientais, de forma não linear e diversificada. 
Explorando a bacia hidrográfica na escola...

Um dos primeiros trabalhos realizados no Brasil enfocando a $\mathrm{BH}$ como unidade geológica onde ocorrem processos biológicos, geológicos e hidrobiológicos, no processo educativo de formação de professores da educação básica, foi o realizado por Tundisi et al. (1988) apud Oliveira (2002). Os projetos e programas de Educação Ambiental com base no conceito de bacias hidrográficas desenvolvidos em São Carlos, SP, desde 1986, demonstram a importância de se trabalhar as sub-bacias locais no aperfeiçoamento de professores dos Ensinos Fundamental e Médio. Essa unidade de estudo e gerenciamento é eficaz como forma de promover o desenvolvimento de projetos interdisciplinares, onde os professores recebem subsídios para atuarem não somente na comunidade escolar como também no bairro (TUNDISI, 2003; SANTOS, RUFFINO, 2003).

A abordagem de bacias hidrográficas neste contexto é referenciada por Ruffino e Santos (2002) como unidades representativas próximas à realidade vivida pelo educador e seus educandos. Segundo os autores, é importante que a bacia hidrográfica a ser trabalhada seja inteiramente conhecida e detalhada. Para tanto, é imprescindível a percepção ambiental em relação aos aspectos biofísicos e antrópicos, tais como o relevo, áreas permeáveis e impermeáveis, densidade de ocupação humana, impactos antrópicos, etc., e levantamentos técnicos da região (solos, geologia, rede hídrica).

Oliveira (2002) coloca a bacia hidrográfica como referencial para a análise dos problemas ambientais e para o ensino e a pesquisa em Educação Ambiental. O ensino e a pesquisa relativos à bacia hidrográfica compreendem o diagnóstico da percepção dos sujeitos envolvidos, levando-se em conta suas dimensões afetivas e estéticas na consolidação para a tomada de decisões no gerenciamento hídrico.

Procurou-se, neste trabalho, contextualizar a sub-bacia do Rio Santo Cristo, município de Giruá, RS, como um sistema complexo, com a interação entre os elementos ecológicos e sociais, por meio da participação de educadores e estudantes dos Ensinos Fundamental e Médio de duas escolas públicas. Por ser um município basicamente agrícola, Giruá conta com uma população rural significativa. Dessa forma, a questão hídrica é de grande interesse na comunidade, sendo que várias escolas desenvolvem projetos nessa área. Com base nesse enfoque, tornou-se relevante o interesse em contribuir na construção de conhecimentos sobre o ambiente local com a participação ativa da comunidade escolar. A opção pela sub-bacia do Rio Santo Cristo ficou a cargo de sua proximidade das escolas, bem como de sua importância na contribuição hídrica de seus afluentes ao longo de outros municípios, dos quais é captada água para abastecimento urbano.

\section{Objetivos}

O objetivo geral do trabalho aqui apresentado foi o desenvolvimento de atividades relacionadas à sub-bacia de um rio, por meio da participação de estudantes e educadores de duas escolas públicas, como subsídio à Educação Ambiental. Para tanto, os seguintes objetivos específicos foram delineados:

1 Formar grupos de professores e alunos-monitores para possíveis efeitos multiplicadores. 
Bergmann, M.; Pedrozo, C. S.

2 Realizar um diagnóstico das características limnológicas, físicas e de nível de impactos ambientais decorrentes de atividades antrópicas na sub-bacia do Rio Santo Cristo como subsídio para a educação ambiental.

3 Verificar como os alunos e os professores respondem a atividades que envolvem o diagnóstico da sub-bacia do rio em questão, identificando possíveis alterações nas concepções dos alunos em relação ao conceito de bacia hidrográfica, qualidade da água e interações existentes nos rios.

\section{Materiais e métodos}

\section{Área de estudo}

O município de Giruá pertence à Região Noroeste do Estado do Rio Grande do Sul, distante 490 quilômetros da capital Porto Alegre. O Rio Santo Cristo está inserido na bacia hidrográfica dos rios Turvo, Santa Rosa e Santo Cristo, situado ao norte do estado, na região hidrográfica do Uruguai. Esse estudo foi desenvolvido no Instituto Estadual de Educação João XXIII e na Escola Municipal de Ensino Fundamental Nicolau Leite, com atividades de Educação Ambiental enfocando a sub-bacia do Rio Santo Cristo. A E.M.E.F. Nicolau Leite conta com 213 alunos, distribuídos desde a educação infantil (Jardim de Infância) até a oitava série do Ensino Fundamental, e corpo docente constituído por 16 professores. O Instituto Estadual de Educação João XXIII conta com 1052 estudantes, distribuídos desde a primeira série do Ensino Fundamental até a terceira série do Ensino Médio. O corpo docente está constituído por 61 professores.

\section{Procedimentos metodológicos}

Para realizar as atividades junto às escolas participantes, delinearam-se os seguintes procedimentos metodológicos: formação de grupos de professores, aula teórica sobre bacias hidrográficas com os alunos, aplicação de protocolo para verificação das características ambientais da sub-bacia hidrográfica, diagnóstico das características limnológicas da sub-bacia do rio, elaboração de material educativo e apresentação dos resultados, pelos estudantes e professores envolvidos, aos demais setores das escolas e comunidade.

O processo inicial da pesquisa deu-se então pela divulgação da proposta a todos os professores das escolas E.M.E.F. Nicolau Leite e I.E.E. João XXIII, juntamente com a equipe diretiva de cada uma. Entretanto, o grupo de participantes ficou restrito a sete professoras, sendo seis delas da escola estadual e uma da municipal, divididas em três áreas de conhecimento: quatro de Ciências e Biologia, duas de Geografia e uma de Língua Portuguesa.

As professoras participantes, por sua vez, tiveram autonomia para optar pelas turmas com as quais gostariam de trabalhar. Dessa forma, foram selecionadas uma turma de primeira série do Ensino Médio e as duas turmas da oitava série do Ensino Fundamental para atuarem como monitoras nas atividades a serem desenvolvidas. Essas turmas foram indicadas levando-se em consideração a possível continuidade das atividades nos anos subseqüentes.

Como início do processo com os estudantes, realizou-se uma aula teórica, conduzida 
pela pesquisadora, com as duas turmas da oitava série, separadamente, e com a turma da primeira série do Ensino Médio (da escola estadual), selecionadas como monitoras. Essa aula teve a duração de cinquenta minutos, e teve seu enfoque na conceituação de bacia hidrográfica e nos aspectos limnológicos de seus cursos de água. Após a exposição teórica em sala de aula, procedeu-se à aplicação de um protocolo de avaliação rápida de trechos de bacias hidrográficas, de acordo com Callisto et al. (2002). As duas turmas da oitava série foram conduzidas ao campo separadas da turma da primeira série, e cada série dividida em seis grupos.

O protocolo consiste em um conjunto de parâmetros que avalia as características físicas e nível de impactos ambientais decorrentes de atividades antrópicas e as condições de habitat e nível de conservação natural, com pontuação entre zero e cinco pontos. A pontuação final é obtida pelo somatório dos valores atribuídos a cada parâmetro observado. O total de zero a quarenta pontos representa "trechos impactados"; de 41 a sessenta pontos, "trechos alterados", e, acima de 61 pontos, os trechos são considerados "naturais".

Com base na pontuação total de cada grupo de alunos, foi feita a avaliação do comportamento das distribuições nas duas turmas (oitava série do Ensino Fundamental e primeira série do Ensino Médio) com o teste de Mann-Whittney, utilizando-se o programa Bioestat 3.0 (AYRES et al., 2003). Para a análise de agrupamento, foi feita análise multivariada com medida de semelhança (índice de Gower) entre unidades amostrais, sendo o número de grupos nítidos observados pelo método Bootstrap, por meio do aplicativo Multiv (PILLAR, 2001).

O diagnóstico das características limnológicas da sub-bacia do rio Santo Cristo também foi acompanhado pelas turmas de oitava série do Ensino Fundamental das duas escolas envolvidas e por uma turma da primeira série do Ensino Médio da escola estadual, juntamente com as professoras participantes. A campanha de coleta de água foi realizada em junho de 2006, em quatro estações de amostragem no Rio Santo Cristo. As variáveis limnológicas analisadas consistiram em: temperatura da água e do ar, condutividade elétrica, $\mathrm{pH}$ e oxigênio dissolvido, alcalinidade, turbidez, cloretos, fósforo total, nitrogênio total e coliformes fecais. Essas variáveis descrevem a condição de poluição orgânica da água do Rio Santo Cristo. As amostras foram acondicionadas em gelo até serem conduzidas aos laboratórios do Núcleo de Alimentos da Universidade Regional da Região Noroeste do Rio Grande do Sul (UNIJUI).

Com base nas saídas a campo para observação das características da sub-bacia hidrográfica em questão, as professoras propuseram a elaboração de um material educativo que pudesse ser disponibilizado à população residente no local. A idéia foi a de um folheto, elaborado com contribuições dos próprios alunos. Buscando uma identificação para o folheto educativo, os alunos do Ensino Médio foram convidados a criar um slogan e uma frase que o representasse. $\mathrm{O}$ desenho foi selecionado com base na criatividade e na retratação do local em estudo.

Selecionado o slogan, realizou-se uma reunião com os alunos-monitores do Ensino Médio para que opinassem e discutissem quais os assuntos mais importantes a serem colocados nos panfletos que seriam distribuídos à comunidade. Todas as turmas do Ensino Médio e a oitava série do Ensino Fundamental foram convidadas a comparecer, em turno inverso ao de seu período de estudo na escola, para a distribuição do material educativo aos moradores do bairro da escola.

Todas essas atividades foram apresentadas pelas professoras e alunos-monitores em eventos locais e regionais por meio da elaboração de resumos e exposição nas escolas. 
Bergmann, M.; Pedrozo, C. S.

\section{Identificação de mudanças nas concepções dos estudantes}

Para identificar possíveis alterações nas concepções dos alunos em relação ao conceito de bacia hidrográfica, um questionário de perguntas abertas foi dirigido às turmas da oitava série do Ensino Fundamental e à turma da primeira série do Ensino Médio, prévia e posteriormente (pré/pós-teste) à sua participação nas atividades de caracterização ambiental da bacia hidrográfica do Rio Santo Cristo. O questionário continha quatro perguntas sobre bacias hidrográficas, interações em um rio, qualidade da água e conhecimento dos cursos d'água locais. As professoras tiveram sua participação pautada no diálogo e na intervenção durante o processo de pesquisa nas escolas.

\section{Resultados e discussão}

A aula teórica sobre bacias hidrográficas e aspectos limnológicos de águas lóticas propiciou, aos alunos da oitava série do Ensino Fundamental e primeira série do Ensino Médio, uma maior compreensão das interações ecológicas neste tipo de ambiente. A localização, no mapa hidrográfico do Estado do Rio Grande do Sul, da bacia onde o município está inserido serviu como base para a explicação dos vários rios que formam a região da Bacia Hidrográfica dos rios Turvo, Santa Rosa e Santo Cristo. Percebeu-se que os alunos não possuíam conhecimento da dimensão de uma rede hidrográfica, tampouco da denominação de tal rede na região. Com base nesse enfoque, o tema "qualidade da água" foi aprofundado, destacando-se a importância das variáveis ambientais indicadoras dessa condição, que seriam medidas em campo.

\section{Resultados da aplicação do protocolo}

Seguindo-se o diagnóstico das características físicas e nível de impactos ambientais na sub-bacia do rio por meio de protocolo, os alunos responderam às 18 questões propostas, pontuando cada observação. Ao final, os valores totais de cada grupo foram quantificados. A pontuação dada pelos alunos da primeira série do Ensino Médio e pela oitava série do Fundamental está descrita nas Tabelas 1 e 2, respectivamente. O total de pontos atribuídos pelas turmas está na Figura 1.

O diagrama de dispersão e o dendrograma (Figuras 2 e 3) mostram que houve uma tendência à formação de dois grupos nítidos. Observa-se que os grupos 9, 11 e 12 (oitava série) constituíram um agrupamento à parte, tendo maiores variações nas pontuações de cada parâmetro do protocolo.

Para avaliar o comportamento das distribuições nas duas turmas, o teste de MannWhittney, também conhecido como Teste U, foi utilizado para o teste de hipóteses, conforme Scatena (2005), sendo elas as seguintes:

Ho: a pontuação média de qualidade ambiental da oitava série é igual à pontuação média da qualidade ambiental da primeira série do Ensino Médio. 
Explorando a bacia hidrográfica na escola...

Tabela 1. Pontuação dada pelos alunos da primeira série do Ensino Médio.

Protocolo de avaliação rápida de trechos de bacias hidrográficas

Escola: Instituto Estadual de Educação João XXIII

Série/Turma: $1^{\text {a }}$ série

Localização: Nascente bairro Leimann

Data de coleta: 16/05/2006

Tempo (situação do dia): Ensolarado

Hora da coleta: 9 às $10 \mathrm{hs}$

Largura do corpo hídrico: 1 a $2 \mathrm{~m}$.

Profundidade: 10 a $20 \mathrm{~cm}$.

Temperatura da água: $15^{\circ} \mathrm{C}$

\begin{tabular}{lcccccc}
\hline \multicolumn{1}{c}{ PARÂMETRO } & Grupo 1 & Grupo 2 & Grupo 3 & Grupo 4 & Grupo 5 & Grupo 6 \\
\hline 1. Tipo de ocupação das margens & 2 & 4 & 2 & 2 & 2 & 4 \\
2. Erosão ou assoreamento & 2 & 2 & 2 & 2 & 2 & 2 \\
3. Alterações antrópicas & 0 & 2 & 2 & 2 & 2 & 2 \\
4. Cobertura vegetal no leito & 2 & 2 & 2 & 2 & 2 & 2 \\
5. Odor da água & 0 & 4 & 4 & 4 & 4 & 4 \\
6. Oleosidade da água & 2 & 2 & 2 & 2 & 2 & 2 \\
7. Transparência da água & 2 & 2 & 4 & 4 & 4 & 2 \\
8. Tipo de fundo & 4 & 2 & 4 & 0 & 4 & 2 \\
9. Diversificação de habitats & 0 & 2 & 0 & 0 & 0 & 0 \\
10. Tipos de substrato & 2 & 0 & 0 & 2 & 0 & 2 \\
11. Freqüência de rápidos & 0 & 0 & 2 & 3 & 2 & 2 \\
12. Deposição de lama & 3 & 0 & 3 & 5 & 5 & 5 \\
13. Depósitos sedimentares & 3 & 5 & 5 & 5 & 5 & 5 \\
14. Alterações no canal do rio & 3 & 3 & 5 & 0 & 2 & 2 \\
15. Fluxo das águas & 3 & 5 & 0 & 2 & 2 & 0 \\
16. Presença de mata ciliar & 3 & 2 & 2 & 2 & 2 & 2 \\
17. Estabilidade das margens & 2 & 2 & 2 & 2 & 2 & 2 \\
18. Extensão de mata ciliar & 2 & 0 & 2 & 2 & 3 & 0 \\
Total de pontos & 35 & 39 & 43 & 43 & 45 & 40 \\
\hline
\end{tabular}

H1: a pontuação média de qualidade ambiental da oitava série é diferente da pontuação média de qualidade ambiental da primeira série do Ensino Médio.

Nível de decisão: $\alpha=0,05$.

Os valores obtidos no Teste de Mann-Whittney podem ser visualizados na Tabela 3 e na Figura 4.

Como o valor de $\mathrm{p}=0,4233$, para $\alpha=0,05$, aceita-se a hipótese de nulidade (Ho). Não há diferença na pontuação média entre as duas turmas de estudantes.

O gráfico (Figura 4) mostra que há uma variabilidade maior na pontuação dos alunos da oitava série do Ensino Fundamental em relação aos da primeira série do Ensino Médio, embora não haja diferença, em média, na pontuação da qualidade ambiental entre ambas as séries. A turma que obteve o melhor resultado esperado foi a primeira série do Ensino Médio, com menor variação entre grupos e entre variáveis, com a classificação geral do trecho da sub-bacia hidrográfica como "alterada". 
Bergmann, M.; Pedrozo, C. S.

Tabela 2. Pontuação dada pelos alunos da oitava série do Ensino Fundamental.

Protocolo de avaliação rápida de trechos de bacias hidrográficas

Escola: Instituto Est. de Educ. João XXIII e Escola Mun. de Ens. Fund. Nicolau Leite

Série: $8^{\mathrm{a}}$

Localização: Nascente bairro Leimann

Data de coleta: 09/06/2006

Hora da coleta: 9 às $10 \mathrm{hs}$
Tempo (situação do dia): Ensolarado

Largura do corpo hídrico: 1 a $2 \mathrm{~m}$.

Profundidade: 10 a $20 \mathrm{~cm}$.

Temperatura da água: $13^{\circ} \mathrm{C}$

\section{PARÂMETRO}

1. Tipo de ocupação das margens

2. Erosão ou assoreamento

3. Alterações antrópicas

4. Cobertura vegetal no leito

5. Odor da água

6. Oleosidade da água

7. Transparência da água

8. Tipo de fundo

9. Diversificação de habitats

10. Tipos de substrato

11. Freqüência de rápidos

12. Deposição de lama

13. Depósitos sedimentares

14. Alterações no canal do rio

15. Fluxo das águas

16. Presença de mata ciliar

17. Estabilidade das margens

18. Extensão de mata ciliar

Total de pontos

\section{Grupo $7 \quad$ Grupo 8}

Grupo 9

Grupo 10

Grupo 11 Grupo 12

4

2

2

2

4

2

2

4
2

3

2

5

5

3

2

3

5

54

2
0
2
2
0
4
4
4
3
0
3
0
3
2
2
2
2
2
37

2
4
2
2
2
0
2
2
0
0
0
2
0
2
0
4
2
5
31

31

2
2
2
2
4
4
2
4
3
2
5
3
2
5
2
3
3
3
53

2
0
2
2
2
2
4
2
0
2
0
5
5
2
0
0
0
0
30

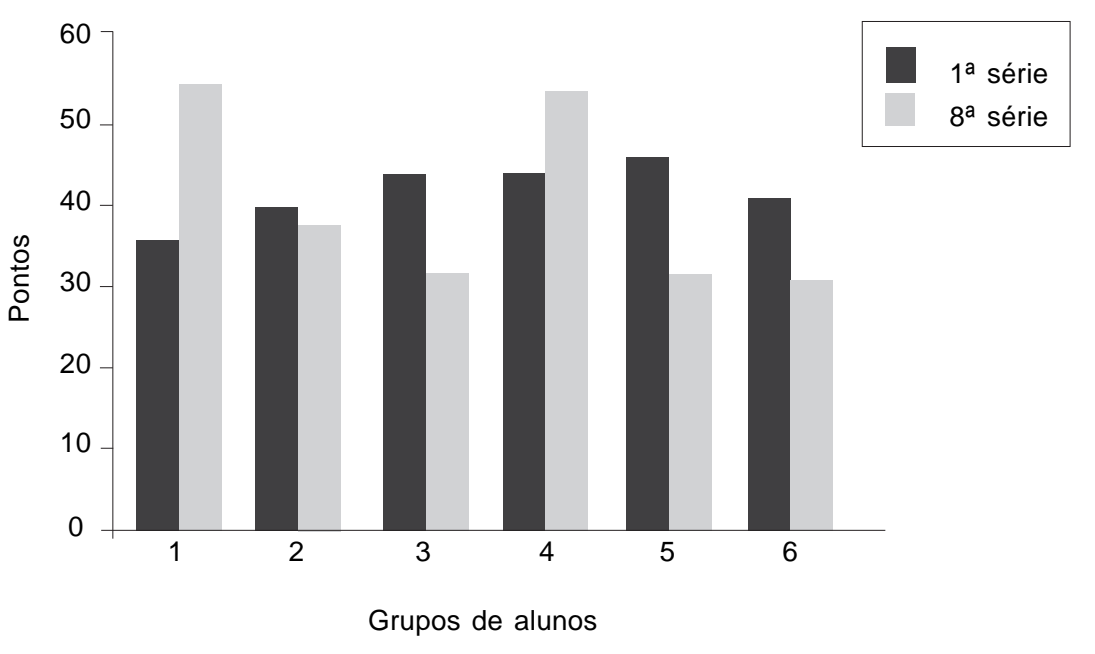

Figura 1. Total de pontos atribuído pelos grupos de alunos. 
Explorando a bacia hidrográfica na escola...
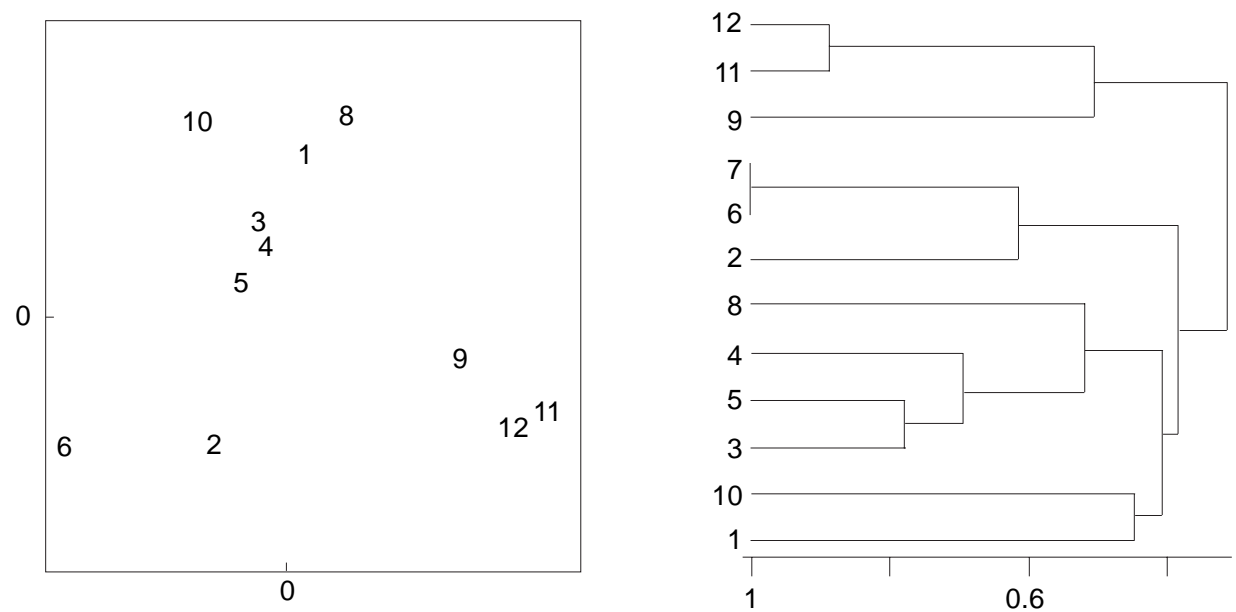

Figuras 2 e 3. Diagrama de dispersão e dendrograma de análise de agrupamento para 12 grupos de alunos.

Tabela 3. Resultado do Teste de Mann-Whittney.

\begin{tabular}{ccccccc}
\hline \multicolumn{10}{c}{ Total de pontos de cada série } \\
\hline N1 & N2 & R1 & R2 & U & Z (U) & $p$ \\
6 & 6 & 34 & 44 & 13 & 0,8006 & 0,4233
\end{tabular}

Como o valor de $p=0,4233$, para $\alpha=0,05$, aceita-se a hipótese de nulidade (Ho). Não há diferença na pontuação média entre as duas turmas de estudantes.

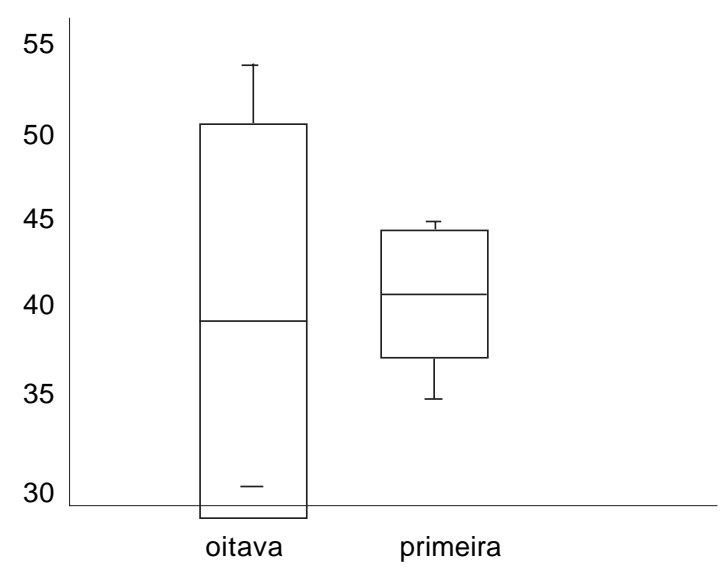

Figura 4. Variação no total de pontos atribuído pela oitava série do Ensino Fundamental e primeira série do Ensino Médio na aplicação do protocolo. 
Bergmann, M.; Pedrozo, C. S.

A maioria dos alunos que realizou esta atividade já havia feito saída a campo à subbacia hidrográfica com a escola, onde, entretanto, os aspectos observados consistiram, sobretudo, no lixo jogado dentro ou às margens do curso d'água. Aspectos como composição ou extensão de mata ciliar, freqüência de rápidos, a composição do fundo e os substratos da água não foram discutidos. A importância do fluxo da água e do tipo de substrato na manutenção dos organismos aquáticos era desconhecida dos alunos, e muitas dúvidas surgiram durante a atividade de campo. Por isso, essa atividade é considerada uma estratégia efetiva na aprendizagem das ciências naturais e na Educação Ambiental, pois envolve e motiva crianças e jovens na exploração do ambiente local. Seniciato e Cavassan (2004) relatam a experiência que tiveram com aulas de campo em um jardim botânico com turmas de sexta série do Ensino Fundamental. Essas aulas propiciaram, aos estudantes, sensações e percepções em relação ao ambiente que não seriam possíveis em sala de aula.

Por meio desta atividade, verificamos que o protocolo de avaliação de riachos é passível de aplicação pelo Ensino Fundamental, além de seu uso pelo Ensino Médio (SCATENA, 2005; MARQUES, 2004) e cursos de graduação (CALLISTO et al., 2002).

\section{Apresentação do diagnóstico da qualidade da água do Rio Santo Cristo aos alunos e professores das escolas participantes}

O resultado da pontuação feita pelos alunos no protocolo foi apresentado juntamente com o diagnóstico da qualidade da água do Rio Santo Cristo aos estudantes e professores das escolas participantes. Enfocaram-se os seguintes aspectos:

1 Os principais impactos antrópicos nos ecossistemas aquáticos que têm provocado a redução da qualidade e da disponibilidade de água, sendo que as principais causas da poluição dos corpos de água são a descarga de efluentes industriais e orgânicos nas áreas urbanas e a degradação da vegetação natural e do solo nas áreas rurais.

2 A escolha e a descrição de cada variável limnológica analisada ( $\mathrm{pH}$, condutividade elétrica, oxigênio etc.) e sua importância para a verificação das condições ambientais dos cursos d'água.

A apresentação da qualidade da água em relação a essas variáveis suscitou algumas indagações. Um dos professores presentes questionou como seriam interpretadas as diferenças de valores de condutividade elétrica nos quatro pontos da amostragem. A explicação foi dada com a participação da professora de química, que disse serem essas diferenças devidas à influência dos agroquímicos utilizados nas lavouras, uma vez que os níveis de condutividade aumentaram do primeiro ao quarto ponto, acompanhando as regiões de lavoura nesses trechos.

Os dados obtidos da análise da água do Rio Santo Cristo estão disponibilizados às escolas, para contribuir nas atividades e nos projetos que venham a ser desenvolvidos pela comunidade escolar no estudo da bacia hidrográfica.

Com base nos resultados das análises da água, os estudantes e professores conclúram que a qualidade da água do Rio Santo Cristo, nos pontos amostrados, apresenta-se comprometida devido ao despejo de esgoto e à utilização de agrotóxicos nas lavouras.

Diante disso, os alunos-monitores relacionaram questões sobre o despejo de resíduos sólidos e a importância da mata ciliar e sua relação com o aspecto da água nos cursos hídricos como temas a serem abordados nos folhetos para distribuição à população. O dese- 
Explorando a bacia hidrográfica na escola...

nho selecionado para o material educativo foi o de uma aluna da primeira série do curso Normal (Magistério), e a frase foi a de um aluno da segunda série do Ensino Médio ("Preserve para ser preservado").

A distribuição dos folhetos à comunidade do bairro da escola foi realizada por dez alunos-monitores indicados e acompanhados pelas professoras, sendo que um total de vinte casas foi visitado. Durante o trabalho de campo, os alunos mostraram-se motivados em realizar a atividade de distribuição do material. A forma como se apresentaram e expuseram o objetivo de sua entrega facilitou o recebimento pelas pessoas, já que o principal interesse nesse processo foi chamar a atenção dos moradores. Dessa maneira, estabeleceu-se uma aproximação entre alunos e comunidade, até então não explorada pelas escolas em suas atividades. Durante o percurso realizado, observou-se que a população era constituída por muitas pessoas advindas do meio rural do município, atualmente aposentadas, além de donas de casa e alguns jovens estudantes. Em suas falas, eles consideram o rio "sujo e poluído", ambiente de proliferação de insetos e outros animais nocivos. Entretanto, reconhecem a importância em preservar o meio local, destinando os resíduos adequadamente.

Além do conhecimento da realidade socioambiental de uma parte do município, essas atividades propiciaram ainda a participação de alunos e professoras em eventos locais e regionais de divulgação científica. Entre eles, destacou-se o projeto "Vivenciando Espaços Escolares", atividade desenvolvida no Instituto Estadual de Educação João XXIII, constituindo-se em um espaço para a integração de projetos e atividades desenvolvidos na escola durante o ano letivo. Aqui, as professoras e estudantes envolvidos no trabalho expuseram aos demais integrantes da instituição os conhecimentos e as ações que foram produzidos e incorporados na interação escola-comunidade. Outra participação importante ocorreu na Feira de Tecnologia, Ciências e Artes do PEIES, em Santa Maria, RS. Essa feira é um espaço disponibilizado para as escolas credenciadas ao PEIES (Programa de Ingresso ao Ensino Superior) da Universidade Federal de Santa Maria. As escolas devem inscrever trabalhos ou projetos sobre quaisquer temas, aplicando métodos técnico-científicos. O trabalho, intitulado como "O meio ambiente no contexto escolar", foi organizado e apresentado por três alunos-monitores do Ensino Médio. A apresentação realizou-se por meio de comunicação oral e audiovisual, e propiciou aos estudantes: compreender o caráter científico de um trabalho de pesquisa; sintetizar as principais etapas e suas respectivas técnicas de forma clara e objetiva; e comunicálo de maneira compreensível.

\section{Resultados do questionário com os alunos}

O questionário dirigido aos alunos da oitava série do Ensino Fundamental e da primeira série do Ensino Médio revelou o que eles conhecem sobre bacia hidrográfica, qualidade da água e sobre os rios da região. As respostas foram agrupadas em categorias, conforme mostram as Tabelas 4, 5, 6 e 7 e respectivas figuras.

A concepção de bacia hidrográfica expressa pelos alunos esteve relacionada à sua definição clássica, que se remete aos aspectos geofísicos e aos recursos hídricos (Tabela 4, Figura 5). A maioria a considerou como "um rio", cuja finalidade de suas águas é o abastecimento das cidades. As respostas dadas no pré-teste continuaram presentes no pós-teste; porém, houve o surgimento de novas expressões. O conceito "é um rio" passou de 57\% para 
Bergmann, M.; Pedrozo, C. S.

$44 \%$, sendo que a conceituação de bacia hidrográfica como sendo "um rio e tudo que tem em volta dele", "uma porção de terra drenada por um rio" e "área de terra que tem água, plantação, casas" revelou que 33\% dos alunos demonstrou alguma alteração em sua concepção do tema.

Quanto às interações e elementos dentro de um rio, a maioria citou seres vivos, como peixes, algas e bactérias, e também relacionou os cursos de água com aspectos negativos, como poluição e animais mortos (Tabela 5, Figura 6). Os aspectos negativos associados aos rios, como "poluição, esgoto, animais mortos" estiveram presentes numa porcentagem significativa (34\% e 28\%), respectivamente, nos testes. Entretanto, a citação de seres vivos, como "peixes", "algas" e "plantas aquáticas" teve um pequeno acréscimo no pós-teste, surgindo também, entre as respostas sobre interações/elementos em um rio, o "oxigênio para os seres vivos" $(4 \%)$.

A concepção dos alunos de que uma água de qualidade é aquela adequada ao consumo humano continuou expressiva no pós-teste (Tabela 6, Figura 7). Contudo, as respostas que indicam a qualidade da água como fundamental à sobrevivência das comunidades biológicas aumentaram entre os estudantes (de 5\% no pré-teste para 19\% no pós-teste), aparecendo também o fator oxigênio como essencial para os seres aquáticos. Um dos alunos demonstrou seu conhecimento sobre certas variáveis particulares de medição de qualidade da água, como o pH e a condutividade elétrica, resultado de sua participação nas coletas realizadas.

A grande maioria dos alunos pesquisados citou somente duas das principais nascentes de rios no município de Giruá, sendo que outras nascentes se encontram no interior da região, próximas dos limites com municípios vizinhos (Tabela 7).

Tabela 4. Freqüência percentual de respostas nas categorias dos testes com os alunos da oitava série do Ensino Fundamental e primeira série do Ensino Médio - Questão 1.

\begin{tabular}{|c|c|c|c|}
\hline Categorias & Questão 1 - Respostas & $\begin{array}{c}\text { Pré-teste } \\
\text { Freqüência percentual } \\
\text { de respostas }\end{array}$ & $\begin{array}{c}\text { Pós-teste } \\
\text { Freqüência percentual } \\
\text { de respostas }\end{array}$ \\
\hline A) Aspecto hídrico & $\begin{array}{l}\text { R1) É um rio. } \\
\text { R2) È onde nasce um rio, } \\
\text { onde se formam os rios. } \\
\text { R3) São os rios e os lagos. } \\
\text { R4) Ė uma rede de água } \\
\text { que abastece a cidade. } \\
\text { R5) É o lençol de água que } \\
\text { tem embaixo da terra. }\end{array}$ & $\begin{array}{l}44 \text { respostas } \\
100 \%\end{array}$ & $\begin{array}{l}29 \text { respostas } \\
67 \%\end{array}$ \\
\hline $\begin{array}{l}\text { B) Curso hídrico e } \\
\text { seu entorno }\end{array}$ & $\begin{array}{l}\text { R6) É um rio e tudo que tem } \\
\text { em volta dele. } \\
\text { R7) É uma porção de terra } \\
\text { drenada por um rio. } \\
\text { R8) Área de terra que tem } \\
\text { água, plantação, casas. }\end{array}$ & 0 & 14 respostas $33 \%$ \\
\hline
\end{tabular}


Explorando a bacia hidrográfica na escola...

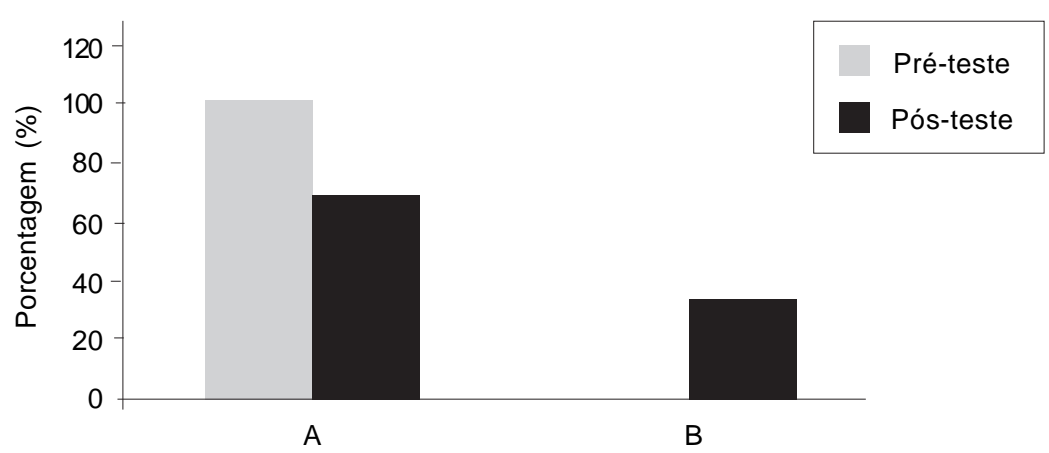

Figura 5. Percentual de respostas nas categorias relativas à Tabela 4.

Tabela 5. Freqüência percentual de respostas nas categorias dos testes com os alunos da oitava série do Ensino Fundamental e primeira série do Ensino Médio - Questão 2.

\begin{tabular}{|c|c|c|c|}
\hline Categorias & $\begin{array}{l}\text { Questão } 2 \\
\text { Respostas }\end{array}$ & $\begin{array}{l}\text { Pré-teste } \\
\text { Freqüência percentual } \\
\text { de respostas }\end{array}$ & $\begin{array}{l}\text { Pós-teste } \\
\text { Freqüência percentual } \\
\text { de respostas }\end{array}$ \\
\hline A) Seres aquáticos & $\begin{array}{l}\text { R1) Peixes. } \\
\text { R2) Algas. } \\
\text { R3) Plantas aquáticas }\end{array}$ & $\begin{array}{c}40 \text { respostas } \\
64 \%\end{array}$ & $\begin{array}{c}52 \text { respostas } \\
67 \%\end{array}$ \\
\hline $\begin{array}{l}\text { B) Animais no } \\
\text { entorno }\end{array}$ & $\begin{array}{l}\text { R4) Existem animais ao } \\
\text { redor do rio. }\end{array}$ & $\begin{array}{l}1 \text { resposta } \\
2 \%\end{array}$ & 0 \\
\hline $\begin{array}{l}\text { C) Produtos de } \\
\text { alterações antrópicas }\end{array}$ & $\begin{array}{l}\text { R5) Poluição, esgoto, } \\
\text { animais mortos, bactérias. }\end{array}$ & $\begin{array}{c}21 \text { respostas } \\
34 \%\end{array}$ & $\begin{array}{c}22 \text { respostas } \\
28 \%\end{array}$ \\
\hline D) Elementos na água & $\begin{array}{l}\text { R6) Oxigênio para os seres } \\
\text { vivos. }\end{array}$ & 0 & $\begin{array}{c}3 \text { respostas } \\
4 \%\end{array}$ \\
\hline
\end{tabular}

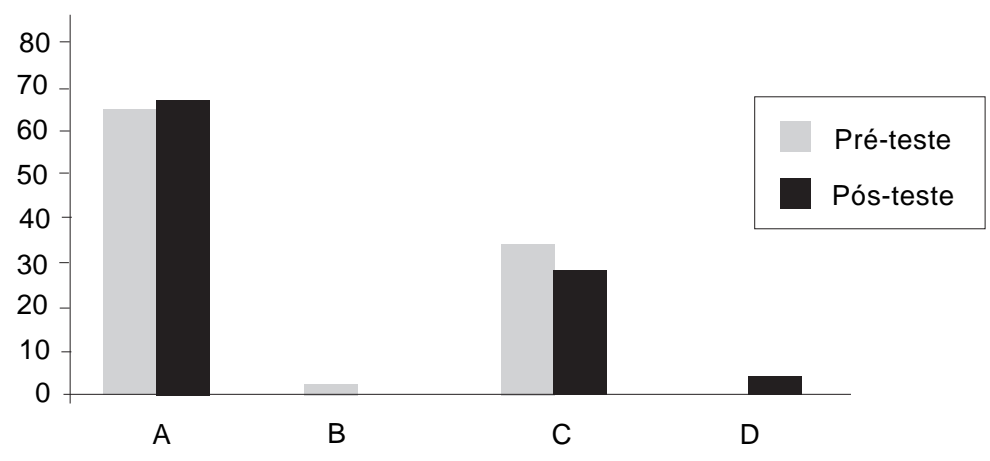

Figura 6. Percentual de respostas nas categorias relativas à Tabela 5. 
Bergmann, M.; Pedrozo, C. S.

Tabela 6. Freqüência percentual de respostas nas categorias dos testes com os alunos da oitava série do Ensino Fundamental e primeira série do Ensino Médio - Questão 3.

\begin{tabular}{|c|c|c|c|}
\hline Categorias & $\begin{array}{l}\text { Questão } 3 \\
\text { Respostas }\end{array}$ & $\begin{array}{l}\text { Pré-teste } \\
\text { Freqüência percentual } \\
\text { de respostas }\end{array}$ & $\begin{array}{c}\text { Pós-teste } \\
\text { Freqüência percentual } \\
\text { de respostas }\end{array}$ \\
\hline $\begin{array}{l}\text { A) Água para } \\
\text { consumo humano }\end{array}$ & $\begin{array}{l}\text { R1) Água boa para beber. } \\
\text { R2) Água limpa e saudável. } \\
\text { R3) Água sem micróbios, } \\
\text { poluição. } \\
\text { R4) Água tratada. } \\
\text { R5) Água que não causa } \\
\text { doenças. } \\
\text { R6) Água potável. }\end{array}$ & $\begin{array}{c}59 \text { respostas } \\
95 \%\end{array}$ & $\begin{array}{c}52 \text { respostas } \\
82 \%\end{array}$ \\
\hline $\begin{array}{l}\text { B) Água com } \\
\text { características } \\
\text { essenciais para as } \\
\text { comunidades } \\
\text { biológicas }\end{array}$ & $\begin{array}{l}\text { R7) Água importante para } \\
\text { os seres vivos. } \\
\text { R8) Água com bastante } \\
\text { oxigênio para os seres } \\
\text { vivos. } \\
\text { R9) O pH e a condutividade } \\
\text { medem a qualidade da água, } \\
\text { para os animais aquáticos. }\end{array}$ & $\begin{array}{c}3 \text { respostas } \\
5 \%\end{array}$ & $\begin{array}{c}12 \text { respostas } \\
19 \%\end{array}$ \\
\hline
\end{tabular}

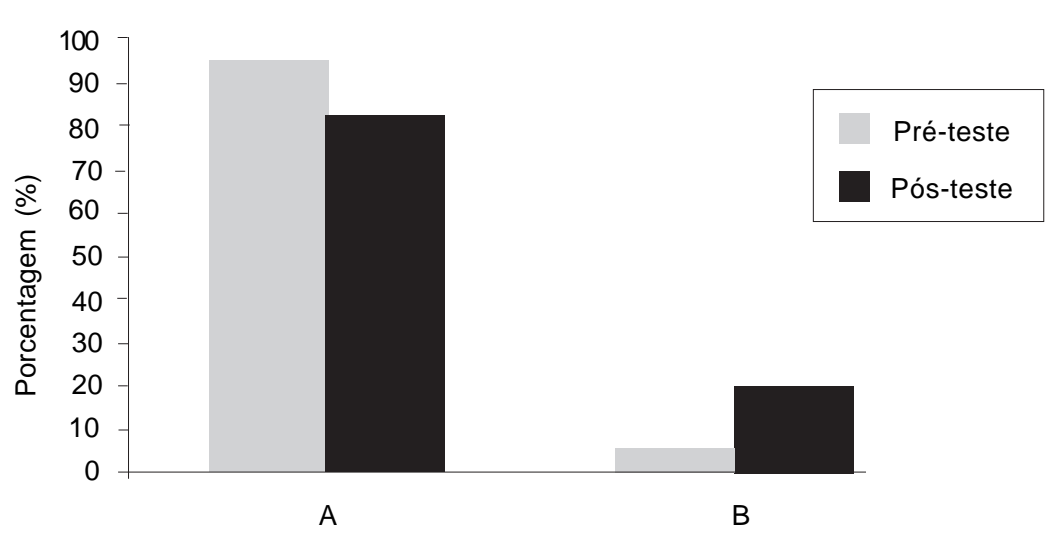

Figura 7. Percentual de respostas nas categorias relativas à Tabela 6 .

As porcentagens de cada categoria em que foram agrupadas as respostas dos estudantes da oitava série do Ensino Fundamental e da primeira série do Ensino Médio mostram que houve variação nas respostas às questões 1, 2 e 3, sugerindo possíveis alterações nas concepções dos alunos após as atividades desenvolvidas relacionadas à sub-bacia do Rio Santo Cristo.

Não se pode afirmar, no entanto, se essas possíveis alterações nas concepções de bacia hidrográfica realmente interferiram na mudança de atitudes e comportamentos dos 
Explorando a bacia hidrográfica na escola...

alunos, ou seja, se sua interação com o ambiente local foi alterada, em suas casas e na escola. Observou-se, porém, que a participação deles nas saídas a campo e nos eventos teve repercussão entre os próprios professores, que muitas vezes não percebem o potencial de seus alunos. Como colocam Tomazello e Ferreira (2001), a avaliação em Educação Ambiental perpassa por vários níveis, sejam eles cognitivos, atitudinais e comportamentais, e requerem não somente uma atividade, mas um processo contínuo em certo período. Com relação aos professores, conforme abordado por Diaz (1995), os processos de Educação Ambiental devem ser avaliados pela capacidade de elaborar e participar de um projeto interdisciplinar, além de apreciar e responder aos interesses da comunidade local. As professoras que optaram por participar do projeto nas escolas mostraram-se um tanto alienadas ao processo, sendo sua participação mais restrita ao acompanhamento nas atividades, e não como colaboradoras no percurso. Apenas uma delas acompanhou de forma mais efetiva as atividades, opinando, interagindo com os alunos em sala de aula, orientando-os em suas motivações, contribuindo na implementação das ações, enfim, atuando como co-pesquisadora. Em diálogo subseqüente às etapas aqui apresentadas, as professoras reconheceram que o processo se deu de forma fragmentada, e sugeriram, como continuidade do projeto, mais entrosamento entre a própria comunidade escolar (alunos, pais, professores e funcionários) e com a comunidade externa, do bairro das escolas e da bacia hidrográfica em estudo.

\section{Considerações finais}

Por intermédio da pesquisa aqui apresentada, verificou-se que o conceito de bacia hidrográfica deve ser trabalhado nas escolas e nos setores comunitários de Giruá, para a compreensão de que a mesma constitui um sistema complexo de interações entre os componentes biológicos, geológicos, hidrológicos e antropogênicos em uma região, contemplandose mais estudos que mostrem à comunidade que a qualidade da água não se refere somente a uma água saudável e que não causa doenças nas pessoas. Ela se refere também à integridade das comunidades biológicas, e isto está relacionado ao seu entorno, à sua vegetação ripáría e aos usos do solo que se fazem do local.

A participação dos estudantes na elaboração de material educativo e na apresentação de suas atividades em eventos mostrou a importância desse processo no aprendizado e na sistematização dos conhecimentos para divulgação dos trabalhos realizados para a comunidade. Portanto, o desenvolvimento de projetos de Educação Ambiental nas escolas requer a consolidação de grupos de professores e de alunos-monitores para atuarem como multiplicadores na geração de conhecimentos sobre o ambiente local e na participação da comunidade nas questões referentes ao meio ambiente. 
Bergmann, M.; Pedrozo, C. S.

\section{Referências}

AYRES, M. et al. Bioestat: aplicações estatísticas nas áreas das ciências biomédicas. Belém: MCT/CNPq, 2003. 1 CD-ROM.

BRASIL. Educação ambiental: curso básico à distância: documentos e legislação da educação ambiental. 2. ed. Brasília: Ministério do Meio Ambiente, 2001. v. 5.

Secretaria da Educação Fundamental. Parâmetros Curriculares Nacionais: apresentação dos temas transversais - Meio Ambiente. Brasília: MEC/SEF, 1997.

CALLISTO, M. et al. Aplicação de um protocolo de avaliação rápida da diversidade de habitats em atividades de ensino e pesquisa, MG-RJ. Acta Limnologica Brasiliensis, São Paulo, v. 14, n.1, p. 91-8, 2002.

DIAZ, A. P. La educación ambiental como proyecto. Barcelona: I. C. E. Universitat Barcelona - Editorial Horsori, 1995.

MARQUES, P. H. C. Integração entre ecologia de bacias hidrográficas e educação ambiental para a conservação dos rios da Serra do Mar no estado do Paraná. 2004. 189f. Tese (Doutorado em Ecologia e Recursos Naturais) Centro de Ciências Biológicas e da Saúde, Universidade Federal de São Carlos, São Carlos, 2004.

OLIVEIRA, H. T. Potencialidades do uso educativo do conceito de bacia hidrográfica em programas de educação ambiental. In: SCHIAVETTI, A.; CAMARGO, A. F. M. (Orgs.). Conceitos de bacias hidrográficas: teorias e aplicações. Ilhéus: Editus, 2002. p. 125-38.

PILLAR, V. P. MULTIV: software para análise multivariada, testes de aleatorização e autoreamostragem "bootstrap". Porto Alegre: Departamento de Ecologia, Universidade Federal do Rio Grande do Sul, 2001.

PIRES, J. S. R.; SANTOS, J. E.; DEL PRETTTE, M. E. A utilização do conceito de bacia hidrográfica para a conservação dos recursos naturais. In: SCHIAVETTi, A.; CAMARGO, A. F. M. (Orgs.). Conceitos de bacias hidrográficas: teorias e aplicações. Ilhéus: Editus, 2002. p. 17-35.

RUFFINO, P. H. P.; SANTOS, S. A. Utilização do conceito de bacia hidrográfica para capacitação de educadores. In: SCHIAVETTTI, A.; CAMARGO, A. F. M. (Orgs.).

Conceitos de bacias hidrográficas: teorias e aplicações. Ilhéus: Editus, 2002. p. 111-23.

SANTOS, S. A. M.; RUFFINO, P. H. P. Proposta do programa de educação ambiental (introdução). In: SCHIEL, D. et al. (Orgs.). O estudo de bacias hidrográficas: uma estratégia para educação ambiental. 2. ed. São Carlos: Rima, 2003. p. 9-13.

SCATENA, L. M. Ações em educação ambiental: análise multivariada da percepção ambiental de diferentes grupos sociais como instrumentos de apoio à gestão de pequenas bacias - estudo de caso da microbacia do córrego da Capituva, Macedônia, SP. 2005. $262 \mathrm{f}$. Tese (Doutorado em Hidráulica e Saneamento) - Escola de Engenharia de São Carlos, São Carlos, 2005. 
Explorando a bacia hidrográfica na escola...

SENICIATO, T.; CAVASSAN, O. Aulas de campo em ambientes naturais e aprendizagem em ciências- um estudo com alunos do ensino fundamental. Ciência \& Educação, Bauru, v. 10, n. 1, p. 133-47, 2004.

TOMAZELLO, M. G. C.; FERREIRA, T. R. C. Educação ambiental: que critérios adotar para avaliar a adequação pedagógica de seus projetos? Ciência $\boldsymbol{\&}$ Educação, Bauru, v. 7, n. 2, p. 199-207, 2001.

TUNDISI, J. G. A bacia hidrográfica como laboratório experimental para o ensino de ciências, geografia e educação ambiental. In: SCHIEL, D. et al. (Orgs.). O estudo de bacias hidrográficas: uma estratégia para educação ambiental. 2. ed. São Carlos: Rima, 2003. p. 3-8.

Artigo recebido em novembro de 2007 e aprovado em maio de 2008. 